\title{
Patient delay among Colombian women with breast cancer
}

\author{
Marion Piñeros, MD, MSc, (I) Ricardo Sánchez, MD, MSc, ${ }^{(1,2)}$ Ricardo Cendales, MD, (I) \\ Fernando Perry, MD,(I) Rocío Ocampo, MD.(I)
}

Piñeros M, Sánchez R, Cendales R, Perry F, Ocampo R. Patient delay among Colombian women with breast cancer. Salud Publica Mex 2009;5 I:372-380.

Piñeros M, Sánchez R, Cendales R, Perry F, Ocampo R. Demora en pacientes colombianas con cáncer de mama. Salud Publica Mex 2009;5 1:372-380.

\begin{abstract}
Objective. Characterize diagnosis and treatment of breast cancer in Bogota, Colombia and examine the extent and determinants of patient delay. Material and Methods. Using a census approach we identified I 106 women with breast cancer. Information was gathered through personal interviews and the review of medical records. Patient delay was defined as the time elapsed from first symptoms to initial consultation Results. More than $80 \%$ of the women (902) consulted due to symptoms; the majority had advanced-stage disease. Patient delay was established in $20.3 \%$ and the main related factors were older age, lack of social security and advanced clinical stage. Higher education in patients was associated with reduced delays. Discussion. Women do not recognize breast cancer symptoms. Patient delay and related factors are similar to those found in other studies. There is an urgent need to develop communication and education strategies regarding breast cancer symptoms and early detection.
\end{abstract}

Key words: Breast cancer; delay; symptoms; detection; health services; Colombia

\section{Resumen}

Objetivo. Caracterizar el diagnóstico y tratamiento de mujeres con cáncer de mama en Bogotá, Colombia; establecer la demora de pacientes en la asistencia a consulta y los factores relacionados. Material y Métodos. A través de una aproximación censal se identificaron I 106 mujeres con cáncer de mama. La recolección de información se hizo mediante entrevistas y revisión de historias clínicas. Se consideró demora de la paciente el tiempo entre la percepción del síntoma y la primera consulta. Resultados. Más de $80 \%$ de las mujeres consultaron por síntomas; la mayoría eran estados avanzados. Los factores que se relacionaron con la demora fueron una mayor edad, no tener afiliación al sistema de salud y la enfermedad avanzada. Una mayor educación se relacionó con menor demora. Discusión. Las mujeres no reconocen los síntomas del cáncer de mama; es necesario diseñar estrategias de comunicación y educación para estimular el reconocimiento de los síntomas y la oportunidad de consulta.

Palabras clave: neoplasias de mama, demora; síntomas; detección; servicios de salud; Colombia

The project was funded entirely by the Colombian government.

(I) Instituto Nacional de Cancerología, Bogotá. Colombia.

(2) Instituto de Investigaciones Clínicas, Universidad Nacional de Colombia.

Fecha de recibido: 30 de marzo de 2009 - Fecha de aprobado: 13 de julio de 2009 Address reprint requests to: Marion Piñeros. Grupo Área de Salud Pública, Instituto Nacional de Cancerología, Calle I No. 9-85, Bogotá, Colombia.

E-mail:mpineros@cancer.gov.co 
$\mathrm{B}^{\mathrm{r}}$ reast cancer is a growing public health problem in many developing countries. In Latin America, mortality and incidence rates are relatively high, indicating that breast cancer cases are diagnosed at late stages or they are not being adequately treated..$^{1,2}$

Today, breast cancer in Colombia is the second cause of cancer deaths among women; mortality is rising, and both incidence and mortality rates show higher risk among women living in large cities. ${ }^{3-5}$ Regarding early detection, clinical breast examination is rarely performed and screening for breast cancer with mammograms is only available for women over 50 years of age who have a general health insurance plan, usually available for employees and their families; therefore, only $37 \%$ of the population has coverage. The rest of the population is covered by subsidized health care plans ( $48 \%$ for low income population), special health care plans (5\% for teachers and military personnel) or medical care in public hospitals for people with no health care plans $(10 \%) .{ }^{6}$ Health care plans are managed through health benefit companies that contract with existing health care centers. A specialized center can provide care for breast cancer patients belonging to different health care plans, depending on existing contracts. Availability of treatment facilities for breast cancer care in the country differ from one region to another and specialized care is delivered only in large capital cities.

Such limited resources is a feature shared by most Latin-American countries and requires efforts in early detection, as has been previously recommended by several institutions and authors. ${ }^{1,7}$ Thus, timely consultation, diagnosis and treatment are crucial.

Despite having access to screening programs, more than $75 \%$ of breast cancer patients consult after symptoms appear. ${ }^{8}$ There is evidence that women who wait more than 3 months for the first consultation have significant lower survival rates than women who seek prompt medical advice. ${ }^{9}$ Total delay includes both patient and provider delay; patient delay is the time elapsed from the moment a symptom or sign is perceived to the first medical consultation and physician delay is the time from first medical contact to final diagnosis and treatment. ${ }^{10}$ Delay in seeking medical advice has been established as one of the reasons for increased cancer mortality in developing countries. ${ }^{11,12}$

Previous studies on patient delay by women with breast cancer have found that the proportion of women that consult after three months ranges from 14 to $19 \%$ in developed countries, ${ }^{13-15}$ while other reports from developing countries have found delays as high as $67 \%$ in Peru ${ }^{16}$ and $42.5 \%$ in Iran. ${ }^{17}$

Common underlying causes related to patient delay are lower education, ${ }^{13,17}$ lower socioeconomic level, ${ }^{17,18}$
African or Hispanic ethnic origin ${ }^{19}$ and symptoms other than a lump., ${ }^{9,14}$ In addition, older age has been related to increased delay in some studies ${ }^{9,20}$ but not in others. ${ }^{21,22}$ Cultural, psychological and spiritual factors undoubtedly influence patient delay as well. 23,24

In the absence of regular breast cancer screening programs, measuring the extent of patient and physican delay and exploring the underlying causes can help to understand barriers to early detection, foster the implementation of appropriate measures and improve breast cancer patient outcome.

We developed a broad descriptive study to outline different diagnosis and treatment aspects, as well as the timing between different stages (first consultation, diagnosis and treatment initiation). Our aim regarding the present component of the study was to determine the time elapsed between symptom perception and first consultation among women with breast cancer, describe the main characteristics of symptomatic women and the primary aspects related to patient delay.

\section{Material and Methods}

The study protocol was accepted by the Ethics Review Board at the Colombian National Cancer Institute in August 2005. Methods will be described for the patient delay component only.

\section{Study design and target population}

We undertook a descriptive study based on a census approach to reach women diagnosed with breast cancer who had already started cancer treatment at health care facilities located in Bogota, Colombia.

A list of all cancer care facilities available for breast cancer patients was obtained from local health authorities. All facilities were approached to explore their interest in the study. Those that agreed to participate were given nine months to recruit patients.

Three general physicians were selected and trained in overall aspects of breast cancer and data gathering procedures. A pilot study was carried out with 20 patients to adjust questionnaires and general procedures.

\section{Data collection and participants}

Patients were recruited from mid January 2006 to June 2007 and grouped according to attendance schedules and appointment lists at each cancer care center. After obtaining written informed consent, a face-to-face structured interview was carried-out during patient visits to health centers. 
Eligible subjects included women with breast cancer under treatment whose first treatment cycle had been administered in Bogota, so as to facilitate medical record checking; women able to answer the questionnaire and women willing to participate were included. We excluded women with bilateral cancer and women with lobular carcinoma in situ, primary sarcomas or breast lymphomas.

Interviews included questions on basic social and demographic aspects, type of affiliation with the health care system, diagnosis and treatment record, type of symptoms or signs, time from symptom to first consultation and reasons for delay.

All women were receiving treatment at the time of the interview; most were interviewed between six months to one year after starting surgical treatment or neoadjuvant chemotherapy.

Women were asked to recall the month and year of their first medical consultation due to breast cancer; this date was used as a reference for questions about whether or not she perceived symptoms, the time symptoms were present before first consultation and socioeconomic factors at the moment of first medical consultation. The main reason for first medical consultation was also established. In symptomatic women, patient delay was defined as the time elapsed between symptoms onset and first medical consultation. Reasons for delay were reported for patients that had waited more than three months after symptoms for first consultation, gathered using open-ended questions that were subsequently coded by three members of the research team.

Each medical record was reviewed in order to extract information about tumor characteristics.

Classification regarding homes was based on public service strata assigned to patient addresses. Such classification ranges from levels 1 to 6 , where 6 corresponds to the highest living conditions standards and 1 and 2 to the lowest.

Clinical staging of the tumor followed the TNM Classification of Malignant Tumors; ${ }^{25}$ stages were grouped in three broad categories: early (stages I-IIA), advanced (stages IIB-IIIC), and metastatic (group IV).

A stable couple was defined as being married or living with the same partner for more than a year.

\section{Statistical analyses}

For simple descriptions, all variables were treated as categorical, with the exception of age that was also analyzed as a quantitative variable. Frequencies were presented as absolute values and percentages.
Associations between categorical variables and patient delay were assessed using contingency tables and chi-square or Fisher exact tests. Strength of association was measured using OR and 95\% confidence intervals.

Logistic regression was applied to estimate adjusted OR using more than 3-month patient delay (yes or no) as the main outcome variable and significance level was set at 0.05 .

All statistical procedures were performed using STATA software.

\section{Results}

\section{Target population}

Sixteen $(73 \%)$ of the cancer care facilities participated in the study; six did not participate, stating that they were not interested in the study and one facility only participated for eight months.

The total number of women identified was 1239 , of which 1106 were eligible. Of the 113 non-eligible women, 58 (43.6\%) had their first treatment cycle outside Bogota, $47(35.3 \%)$ did not agree to participate or were not in conditions to answer the questionnaire, $19(14.3 \%)$ had bilateral cancers and $9(6.8 \%)$ were excluded due to the histological type of cancer.

Of the 1106 eligible women, 899 (81.3\%) had symptoms, $113(10.2 \%)$ had signs detected by a physician and $94(8.5 \%)$ had signs detected through screening. Of the 899 symptomatic women, eight did not remember the date of symptoms onset.

The characteristics of symptomatic women are shown in Table I. The majority $(65.4 \%)$ was affiliated with a general health care plan, $70.5 \%$ had completed high school and $49.5 \%$ belonged to socioeconomic level 3 or higher. Although most cancers were detected at advanced stages, we found a significant association between having a general health care plan and early stage (OR 0.38, CI 95\% 0.25-0.58), which was also true for women with special health care plans (OR 0.26, CI 95\% 0.15-0.46).

Of all eligible women, $899(81.3 \%)$ consulted due to symptoms, $113(10 \%)$ had signs that were detected in a medical consultation due to complaints not related to their breast and $94(8.5 \%)$ had cancer detected through screening during clinical breast examination or by mammogram. Among symptomatic women, the most common symptoms were: lump $(80.4 \%)$, pain $(7 \%)$, changes in breast skin $(3 \%)$, discharge $(2.5 \%)$, changes in nipple $(2.3 \%)$, and other symptoms $(4.5 \%)$ such as pain in the arm, underarm lumps or others. 
Table I

DESCRIPTION OF STUDY POPULATION, DELAY IN SYMPTOMATIC BREAST CANCER PATIENTS. BOGOTA, Colombia, 2008.

\begin{tabular}{lcr} 
Total & 89 I \\
\hline $\begin{array}{l}\text { Age at diagnosis } \\
<50\end{array}$ & 374 & \\
\hline $50-65$ & 357 & \\
\hline$>65$ & 160 & \\
\hline Mean & 53.4 & Sd II.9 \\
& & \\
Education & & \\
Elementary & 317 & 35.6 \\
\hline Secondary-High school & 31 I & 34.9 \\
\hline Technical & 76 & 8.5 \\
\hline University & 115 & 12.9 \\
\hline Postgraduate & 39 & 4.4 \\
\hline NK/NR & 33 & 3.7 \\
$\quad$ Social security & & \\
$\quad$ Not covered & & \\
\hline Subsidized & 155 & 17.4 \\
\hline General health plan - employees & 583 & 65.4 \\
\hline Special & 74 & 8.3 \\
\hline Stable couple & 79 & \\
Yes & & \\
\hline No & & \\
\hline NK/NR & & \\
\hline
\end{tabular}

Socioeconomic classification of housing

\begin{tabular}{lrr}
1 & 88 & 9.9 \\
\hline 2 & 294 & 33.0 \\
\hline 3 & 299 & 33.6 \\
\hline 4 & 89 & 10 \\
\hline 5 & 35 & 3.9 \\
\hline 6 & 18 & 2.0 \\
\hline NK/NR & 68 & 7.6
\end{tabular}

Stage at diagnosis

\begin{tabular}{lrr} 
In situ & II & 1.2 \\
\hline I - IIA & 209 & 23.5 \\
\hline IIB-IIIC & 568 & 63.8 \\
\hline IV & 45 & 5.1 \\
\hline Without information & 58 & 6.5
\end{tabular}

Duration of symptoms

\begin{tabular}{lrr}
$<$ I month & 588 & 66 \\
\hline I to 3 months & 122 & 13.7 \\
\hline$>3$ months & 181 & 20.3
\end{tabular}

NK/NR= Doesn't know/Doesn't respond
Time of consultation and reasons for delay

The majority (65.9\%) of symptomatic women consulted within the first month, $13.8 \%$ consulted within the first three months and $20.3 \%$ waited for more than three months.

The most frequent reasons for delay among women with a more than 3-month-delay were: not considering symptoms to be important (32.9\%), a lump that did not hurt $(28.2 \%)$, fear of cancer diagnosis $(7.9 \%)$ and time constraints $(7.6 \%)$ (Table II); six women mentioned having personal difficulties, explaining that they were caregivers either of elderly persons or of children and didn't want to leave them alone; for another 5 women, it was not possible to identify a clear factor and despite further questioning they said they "did not want to" visit a medical doctor or a health service.

Comparison of symptoms between women who waited less than one month for first consultation and those who waited more than three months did not show significant differences ( $p=0.35$; data not shown).

\section{Factors related to delay}

Bivariate analysis showed the following sociodemographic variables as statistically associated with delay: older age ( $>65$ years) $(p=0.019)$, lower education level $(p=0.000)$, poorer housing conditions $(p=0.011)$ and no affiliation with the health care system $(p=0.005)$. Diagnosis at advanced stages was also associated with delay ( $p=0.000$ ), while not having a stable partner was not associated with delay $(p=0.987)$ (Table III).

Table II

MAIN REASONS FOR PATIENT DELAY IN WOMEN WITH BREAST CANCER. Bogota, Colombia, 2008.

Main reasons for delay

Patient delay $>3$ months

\begin{tabular}{lcc} 
& $n$ & $\%$ \\
Did not consider symptoms important & 57 & 31.8 \\
\hline Lump that did not hurt & 56 & 31.3 \\
\hline Fear of a cancer diagnosis & 18 & 10.1 \\
\hline Time constraints & 10 & 5.6 \\
\hline Administrative problems & 9 & 5.0 \\
\hline Personal difficulties & 6 & 3.4 \\
\hline Personal decision (didn't want to) & 5 & 2.8 \\
\hline Lack of money & 3 & 1.7 \\
\hline Others & 15 & 8.4 \\
\hline All reasons & 179 & 100
\end{tabular}


Table III

Factors Related to patient delay in Symptomatic WOMEn With BREASt CANCER. Bogota, Colombia, 2008.

\begin{tabular}{|c|c|}
\hline elay $<3$ months & Delay $>3$ months \\
\hline$\%$ (row) & $\%$ (row) \\
\hline
\end{tabular}

Age

\begin{tabular}{lllllll}
$<50$ & 323 & 83 & 66 & 16.9 & 389 & 0.019 \\
\hline $50-65$ & 283 & 79.1 & 75 & 20.9 & 358 & 144 \\
\hline$>65$ & 104 & 72.2 & 40 & 27.8 & 891
\end{tabular}

Education

\begin{tabular}{lrrrrrr} 
Elementary & 225 & 70.9 & 92 & 29.1 & 317 & 0.000 \\
\hline Secondary-High school & 255 & 81.9 & 56 & 18.1 & 311 & 76 \\
\hline Technical/ & 64 & 84.2 & 12 & 15.8 & 115 & 39 \\
\hline University & 104 & 90.4 & 11 & 9.6 & & \\
\hline Postgraduate & 37 & 94.9 & 2 & 5.1 & 891
\end{tabular}

Affiliation

\begin{tabular}{lrrrrrr} 
General health plan - employees & 454 & 82.6 & 96 & 17.4 & 550 & 0.005 \\
\hline Special & 61 & 82.4 & 13 & 17.6 & 74 & 155 \\
\hline Subsidized & 120 & 77.4 & 35 & 22.6 & 79 \\
\hline No affiliation & 52 & 65.8 & 27 & 34.2 & 33 \\
\hline Other & 23 & 69.7 & 10 & 30.3 & 891
\end{tabular}

Housing SE classification

\begin{tabular}{rrrrrrr}
1 & 63 & 71.6 & 25 & 28.4 & 88 & 0.011 \\
\hline 2 & 227 & 77.2 & 67 & 22.8 & 294 & 299 \\
\hline 3 & 240 & 80.3 & 59 & 19.7 & 89 & 35 \\
\hline 4 & 79 & 88.8 & 10 & 11.2 & 18 & 68 \\
\hline 5 & 33 & 94.3 & 2 & 5.7 & 11.1 & 891
\end{tabular}

Stable couple

\begin{tabular}{ccccccc} 
Yes & 395 & 79.6 & 101 & 20.4 & 496 & 0.983 \\
\hline No & 314 & 79.7 & 80 & 20.3 & 394 & \\
\hline NK & 1 & 100 & & & & \\
\hline Total & 710 & 79.7 & 181 & 20.3 & 891
\end{tabular}

Stage at diagnosis

\begin{tabular}{lrrrrrr} 
Early & 193 & 87.7 & 27 & 12.27 & 220 & 0.001 \\
\hline Advanced & 437 & 76.9 & 131 & 23.1 & 568 & 45 \\
\hline Metastasic & 32 & 71.1 & 13 & 28.9 & 58 & \\
\hline Nk & 48 & 82.8 & 10 & 17.2 & 891
\end{tabular}

* Comparisons made by Pearson $\mathrm{ji}^{2}$ 
A multivariate comparison of factors affecting patients waiting less than three months (reference group) with those waiting more than three months showed significantly greater breast cancer risks among individuals with lower education levels (elementary education) than among those with higher education levels (postgraduate) (elementary: aOR 4.7 CI 95\% 1.04-2.19). Women affiliated with the health care system through special health care plans also had significantly greater risks (aOR 2.06 CI 95\% 1.00-4.22) (Table IV).

Table IV

FACTORS RELATED TO PATIENT DELAY IN SYMPTOMATIC BREAST CANCER PATIENTS, (ODDS REGRESSION > 3 MONTHS versus <3 months). Bogota, Colombia, 2008.

\begin{tabular}{lcc}
$\begin{array}{l}\text { Determinants } \\
\text { Age }\end{array}$ & COR & aOR \\
$<50$ & 1.0 & 1.0 \\
\hline 50 to 65 & $1.27(.82-1.98)$ & $1.28(.82-2.00)$ \\
\hline$>65$ & $1.56(.877-2.77)$ & $1.46(.79-2.66)$
\end{tabular}

Education

\begin{tabular}{lcc} 
Postgraduate & 1.0 & 1.0 \\
\hline Primary & $7.56(1.76-3.20)$ & $4.77(1.04-2.19)$ \\
\hline Secondary-High school & $4.06(0.95-1.73)$ & $3.47(0.77-1.55)$ \\
\hline Technical/ & $3.46(0.75-1.63)$ & $3.20(0.64-1.58)$ \\
\hline University & $1.95(0.4-9.24)$ & $1.92(0.39-9.47)$
\end{tabular}

Affiliation health system

\begin{tabular}{lcc} 
General health plan - employees & \multicolumn{1}{c}{ I.0 } & \multicolumn{1}{c}{ I.0 } \\
\hline Subsidized & $\mathrm{I} .3(.89-2.14)$ & $.79(.44-1.42)$ \\
\hline Special & $\mathrm{I} .0 \mathrm{I}(.53-1.91)$ & $2.06(\mathrm{I} .00-4.22)$ \\
\hline No affiliation & $2.46(\mathrm{I} .46-4.14)$ & $\mathrm{I} .8 \mathrm{I}(.97-3.38)$
\end{tabular}

Housing classification

\begin{tabular}{ccc}
6 & 1.0 & 1.0 \\
\hline 1 & $1.81(.34-9.56)$ & $1.54(.28-8.40)$ \\
\hline 2 & $1.87(.38-9.08)$ & $1.63(.32-8.16)$ \\
\hline 3 & $1.51(.32-7.14)$ & $1.37(.28-6.69)$ \\
\hline 4 & $1.01(.19-5.35)$ & $.97(.18-5.30)$ \\
\hline 5 & $.59(.07-4.80)$ & $.61(.07-5.14)$
\end{tabular}

\begin{tabular}{lcc}
$\begin{array}{l}\text { Staging } \\
\text { Early }\end{array}$ & 1.0 & 1.0 \\
\hline Advanced & $2.1(1.3-3.3)$ & $1.79(1.08-2.97)$ \\
\hline Metastasic & $2.9(1.3-6.2)$ & $2.51(1.01-6.22)$
\end{tabular}

\section{Discussion}

In the present study, $81.3 \%$ of women with breast cancer mentioned having symptoms that led to diagnosis. Such a high proportion may be explained by the fact that there is no organized breast cancer screening program; nevertheless, it has been established that symptombased detection of breast cancer is still very important in countries where an organized screening program does exist. ${ }^{5,8}$

Patient delay was found in $20.3 \%$ of women with symptomatic breast cancer, which is slightly higher compared to the 14 to $19 \%$ range observed in developed countries $^{13-15}$ but lower than those observed in developing countries such as Thailand $(26.6 \%),{ }^{26}$ Peru $(60 \%)^{16}$ and Iran $(42.5 \%$ and $25 \%) .{ }^{17,27}$

Although patient delay was found only in $20 \%$ of the women, the majority had advanced-stage disease at diagnosis, a situation that may have several explanations. Given that the most important symptom was the presence of a lump, results could indicate that women recognize breast cancer symptoms only very late; this may be related to low self-exploring behavior, which was not addressed in the present study. In Colombia, only $24.5 \%$ of women aged 18 to 69 years perform breast self-examination (BSE) on a regular basis, with a significantly higher percentage among more educated women $(30 \%)$ than among less educated $(14 \%) .{ }^{28}$ Several studies have found that women who experience symptoms other than a lump are prone to longer delays. ${ }^{23}$ This was not the case in this study, probably because almost all symptomatic women had a lump, and when analyzed separately, the other symptoms did not show enough statistical power. The presence of a lump as the most common symptom should direct attention towards the importance of clinical breast examination (CBE) as a means for early detection. In general, one may expect more breast cancers to be detected by physicians than by women. Unfortunately, physical breast examination in Colombia is not offered in an extensive way. Breast cancer early detection guidelines recently issued by the $\mathrm{NCI}$ in Colombia stress the need for comprehensive early detection, where CBE should be offered to every woman in contact with health care services, and reinforced by BSE and timely mammograms. ${ }^{29}$

The high proportion of advanced-stage disease in the absence of a high prevalence of patient delay may also indicate significant provider delay. In fact, the broader study showed that provider delay was very high (data not yet published). 
Finally, the possibility of having underestimated patient delay can not be ruled out, as women were interviewed after they had begun treatment and they may have been subject to recall bias.

We found that $67.3 \%$ of patients were women with general health care plans, which means they were either employees or beneficiaries of an employee. A similar distribution of breast cancer cases among women with this same health care plan was found in another Colombian study. ${ }^{30}$ Ultimately, this reflects higher breast cancer prevalence in populations with better socioeconomic conditions, which has also been observed in other countries. ${ }^{31}$ Higher prevalence of reproductive and lifestyle breast cancer risk factors, as well as a higher incidence risk, may be due to specific employment conditions. ${ }^{32}$

In addition, patients affiliated with general health care plans have better access to health services and, therefore, greater chances of breast cancer diagnosis. We observed significant differences in disease staging depending on the type of affiliation with the health system, e.g., women with general health care plans had less advanced cancers than those with a subsidized health care plan or those not affiliated at all. As mentioned before, this population has a lower socioeconomic status (SES), which has been associated with advanced disease in Colombia and elsewhere. ${ }^{33,34}$ Furthermore, present Colombian health care system guidelines regarding breast cancer screening are clearly not equitable, as women with poorer socioeconomic conditions are not offered screening. Lack of access to health care services has also been established as a strong predictor of cancer screening underutilization among the U.S. Latino population..$^{35}$ Nevertheless, breast cancer mortality in Colombia is also higher among women with general health care plans, unlike mortality observed for cervical cancer. ${ }^{36}$

The main reasons for patient delay found in this study were either that women did not believe symptoms to be important or that the lump did not hurt. These findings, together with late stage at diagnosis, point towards women ignoring the seriousness of a painless lump, an observation made in several other studies in developing countries. ${ }^{37,38}$ The patient's initial interpretation of a lump as not serious seems to be a common factor for delay. ${ }^{24}$ A previous Colombian study showed that women, particularly in low socioeconomic levels, did not recognize symptoms or did not link them to the possibility of having breast cancer. ${ }^{34}$

In addition, present study found that poor housing conditions, low education and lack of affiliation were related to patient delay; all three of which are associated with low socioeconomic status, which has been related to delay in some studies but not in others. ${ }^{24}$
In other studies, particularly in a Latin-American study, fear was mentioned as an important cause of delay; ${ }^{16,24}$ that was not the case in our study. Delay could also reflect waiting related to a self-monitoring behavior, as has been shown in other studies, ${ }^{39}$ this was not explored in the present study.

\section{Limitations}

The number of non-participating centers (27\%) due to our study design may be related to a selection bias; nevertheless, in the present Colombian health system a single institution, in this case a specialized cancer care center, provides care for populations with different health plans, and given that few cancer care centers provide complete treatment (surgery, radiotherapy and chemotherapy), the probability that a patient with breast cancer is treated in two or more institutions is very high. One of the institutions that did not participate in the study offers care only to women with special health plans. Based on these observations, we believe that our results could be generalized to breast cancer patients treated in Bogota under general health care plans and subsidized health care plans, as well as to patients not covered by such plans, which together account for $95 \%$ of the population.

The second limitation worth mentioning is the possibility of recall bias, as most of the variables relied upon information given by patients, and establishing the date of symptoms onset is not easy. This, unfortunately, is a problem shared by many other studies due to the design used. Nevertheless, as all women had already begun treatment when interviewed and were in similar treatment stages, the possibility of a differential recall bias may have been reduced. ${ }^{40,41}$

As patient delay was part of a broader general descriptive study, aspects that could have contributed to a better understanding of delay, such as consulting a family member or friend with breast cancer, attending a health care facility in the previous year, or performing regular BSE, were not explored.

\section{Conclusions}

Most breast cancer patients were symptomatic and in advanced stages at diagnosis, even in a city where women have better levels of education and access to health care.

Patient delay seems to be within "acceptable ranges" as compared to findings from studies in other countries. The reasons for delay in our study suggest that women do not consider symptoms important and do not recognize warning signs of breast cancer. 
Our findings support the need to strengthen early breast cancer detection and education and information strategies on breast cancer symptoms in order to improve indicators regarding advanced stages. A more complete analysis of the main problems of delay in breast cancer treatment in Bogota will be provided after completing a provider delay analysis as part of the general study.

\section{Acknowledgements}

We thank the patients and staff at the different health care centers, as well as Diana Cuenca, Germán Barbosa and Gabriel Castellanos for their help in the project.

\section{References}

I. Robles SC, Galanis E. Breast cancer in Latin America and the Caribbean. Rev Panam Salud Publica 2002; I (3): 178- 185.

2. Schwartsmann G. Breast cancer in South America: challenges to improve early detection and medical management of a public health problem.J Clin Oncol 2001;19(I8 Suppl): I 18S-124S.

3. Pineros M, Hernandez G, Bray F. Increasing mortality rates of common malignancies in Colombia: an emerging problem. Cancer 2004; I0I(I0):2285-2292.

4. Murillo R, Piñeros M, Hernández G.Atlas de mortalidad por cáncer en Colombia. Bogotá: Imprenta Nacional, 2004.

5. Ferlay J, Bray F, Pisani P, Parkin DM. GLOBOCAN 2002 Cancer Incidence, Mortality and Prevalence Worldwide, version 2.0. Lyon: IARC Press, 2004; Vol 5.

6. Asociación Colombiana de Empresas de Medicina Integral. Situación actual y retos del sistema de aseguramiento de la salud en Colombia. ACEMI 2008 October 22 [consulted 2009 May 20]. Available at: URL: www.alami.org/subidos/documentos $3 /$

7. Anderson BO. Breast healthcare and cancer control in limited-resource countries: a framework for change. Nat Clin Pract Oncol 2006;3(I):4-5.

8. Richards MA, Westcombe AM, Love SB, Littlejohns P, Ramirez AJ.

Influence of delay on survival in patients with breast cancer: a systematic review. Lancet 1999;353(9159): I I |9- I 26.

9. Ramirez AJ,Westcombe AM, Burgess CC, Sutton S, Littlejohns P, Richards MA. Factors predicting delayed presentation of symptomatic breast cancer: a systematic review. Lancet 1999;353(9 |59): I | 27- I | 3 | 10. Facione NC, Miaskowski C, Dodd MJ, Paul SM. The self-reported likelihood of patient delay in breast cancer: new thoughts for early detection. Prev Med 2002;34(4):397-407.

I I. Boffetta P, Parkin DM. Cancer in developing countries. CA Cancer J Clin 1994;44(2):81-90.

12. Malik IA, Gopalan S. Use of CAM results in delay in seeking medical advice for breast cancer. Eur J Epidemiol 2003; |8(8):8/7-822.

13. Arndt V, Sturmer T, Stegmaier C, Ziegler H, Dhom G, Brenner H. Patient delay and stage of diagnosis among breast cancer patients in Germany -- a population based study. Br J Cancer 2002;86(7): 1034-1040. 14. Burgess CC, Ramirez AJ, Richards MA, Love SB. Who and what influences delayed presentation in breast cancer? $\mathrm{Br} J$ Cancer 1998;77(8):1343-1348.

15. Meechan G, Collins J, Petrie K. Delay in seeking medical care for self-detected breast symptoms in New Zealand women. N Z Med J 2002;। I5(II66):U257.
16. Contreras NR,Valdeiglesias N. Demora en el diagnóstico de cáncer de mama: factores de la paciente. Hospital EsSalud Cusco 1986-1999. Situa 2000(I5). [Consultado 2009 marzo 20]. Available at: http://sisbib.unmsm. edu.pe/BVRevistas/situa/2000_n15/diagnostico.htm

17. Harirchi I, Ghaemmaghami F, Karbakhsh M, Moghimi R, Mazaherie H. Patient delay in women presenting with advanced breast cancer: an Iranian study. Public Health 2005; I I9(10):885-89I.

18. Lannin DR, Mathews HF, Mitchell J, Swanson MS, Swanson FH, Edwards MS. Influence of socioeconomic and cultural factors on racial differences in late-stage presentation of breast cancer. JAMA 1998;279(22): 180I-1807. 19. Mandelblatt J, Andrews H, Kerner J, Zauber A, Burnett W. Determinants of late stage diagnosis of breast and cervical cancer: the impact of age, race, social class, and hospital type. Am J Public Health 1991;81(5):646-649.

20.Arndt V, Sturmer T, Stegmaier C, Ziegler H, Dhom G, Brenner H. Socio-demographic factors, health behavior and late-stage diagnosis of breast cancer in Germany: a population-based study.J Clin Epidemiol 200I;54(7):719-727.

21. Hansen RP, Olesen F, Sorensen HT, Sokolowski I, Sondergaard J. Socioeconomic patient characteristics predict delay in cancer diagnosis: a Danish cohort study. BMC Health Serv Res 2008;8:49.

22. Neal RD,AllgarVL. Sociodemographic factors and delays in the diagnosis of six cancers: analysis of data from the "National Survey of NHS Patients: Cancer”. Br J Cancer 2005;92(I I): 197|-1975.

23. Friedman LC, Kalidas M, Elledge R, Dulay MF, Romero C, Chang J, et al. Medical and psychosocial predictors of delay in seeking medical consultation for breast symptoms in women in a public sector setting. J Behav Med 2006;29(4):327-334.

24. Unger-Saldaña K, Infante-Castaneda C. Delay of medical care for symptomatic breast cancer:A literature review. Salud Publica Mex 2009;5 I (Suppl 2):270-285.

25. UICC International Union Against Cancer.TNM Classification of Malignant Tumours. 6th ed. USA:Wiley \& Sons, 2002.

26. Thongsuksai P, Chongsuvivatwong V, Sriplung H. Delay in breast cancer care: a study in Thai women. Med Care 2000;38(I):108-I I4.

27. Montazeri A, Ebrahimi M, Mehrdad N,Ansari M, Sajadian A. Delayed presentation in breast cancer: a study in Iranian women. BMC Womens Health 2003;3(I):4.

28. Ojeda G, Ordoñez M, Ochoa LF. Encuesta Nacional de Demográfía y Salud 2005. Bogota, DC, Colombia: Profamilia, 2007.

29. Instituto Nacional de Cancerología. Recomendaciones para la detección temprana del cáncer de mama en Colombia. Guías de práctica clínica. Bogota: INC, 2006: I.

30. Charry LC, Carrasquilla G, Roca S. Equity regarding early breast cancer screening according to health insurance status in Colombia. Rev Salud Publica 2008; 10(4):57I-582.

3I. Reynolds P, Hurley SE, Quach AT, Rosen H,Von BJ, Hertz A, et al. Regional variations in breast cancer incidence among California women, 1988-1997. Cancer Causes Control 2005; 16(2): I39-150.

32. Kogevinas M, Pearce N, Susser M, Boffetta P. Social inequalities and cancer: a summary by the editors. Scientific Publication No. I38. Lyon: IARC, 2009:I-16.

33. Baquet CR, Commiskey P. Socioeconomic factors and breast carcinoma in multicultural women. Cancer 2000;88(5 Suppl):1256-I 264. 34.Wiesner C. Determinantes psicológicos, clínicos y sociales del diagnóstico temprano del cáncer de mama en Bogotá, Colombia. Rev Col Cancerol 2007; I (I): 13-22.

35. Rodriguez MA, Ward LM, Perez-Stable EJ. Breast and cervical cancer screening: impact of health insurance status, ethnicity, and nativity of Latinas.Ann Fam Med 2005;3(3):235-24I.

36. Murillo R, Díaz S, Sánchez O, Perry F, Piñeros M, Poveda C, et al. Pilot Implementation of Breast Cancer Early Detection Programs in Colombia. Breast Care 2009;29-32. 
37. Montazeri A,Vahdaninia M, Harirchi I, Harirchi AM, Sajadian A, Khaleghi $F$, et al. Breast cancer in Iran: need for greater women awareness of warning signs and effective screening methods. Asia Pac Fam Med 2008;7(I):6.

38. Ukwenya AY,Yusufu LM, Nmadu PT, Garba ES, Ahmed A. Delayed treatment of symptomatic breast cancer: the experience from Kaduna, Nigeria. S Afr J Surg 2008;46(4): 106-I I0.

39. Timko C. Seeking medical care for a breast cancer symptom: determinants of intentions to engage in prompt or delay behavior. Health Psychol 1987;6(4):305-328.
40. Barry D. Differential recall bias and spurious associations in case/ control studies. Stat Med 1996;15(23):2603-26I6.

4I. Lewis BG, Halm EA, Marcus SM, Korenstein D, Federman AD.

Preventive services use among women seen by gynecologists, general medical physicians, or both. Obstet Gynecol 2008; I I (4):945-952 . 